\title{
Seismicity induced by hydraulic fracturing and wastewater disposal in the Appalachian Basin, USA: a review
}

\author{
Michael R. Brudzinski ${ }^{1}$ Maria Kozłowska² ${ }^{2}$
}

Received: 30 May 2018 / Accepted: 14 January 2019 / Published online: 28 January 2019

(c) The Author(s) 2019

\begin{abstract}
Eastern Ohio is an area of North America where a significant increase in seismicity rate was noted in the early 2010s. This increase has been associated with intensification of unconventional gas extraction performed in the Appalachian Basin and has been directly linked to two processes: hydraulic fracturing and disposal of the associated wastewater. In this paper, we review the recent seismicity in the Appalachian Basin including various episodes of induced seismicity that were temporally and spatially linked to operational activity, and we have performed some comparable analyses on the most recent sequences. The activities have not been as pervasive as other areas of North America, such that the cases are typically isolated and provide opportunities to study the seismogenic process in detail. The observed seismicity is concentrated in a narrow corridor that extends north-south in eastern Ohio and into central West Virginia, perhaps due to differences in operational targets and geologic variations. Ohio appears to have a higher prevalence of seismicity induced by wastewater disposal than surrounding states, but this is based on limited number of cases. Ohio also has an order of magnitude higher prevalence of seismicity induced by hydraulic fracturing than surrounding states, and prior work has suggested this is due to the targeting of the deeper Utica-Point Pleasant formation in Ohio that is closer to basement rocks than the Marcellus formation in West Virginia or Pennsylvania. In areas where hydraulic fracturing has induced seismicity, the percentage of stimulated wells that produce detectable seismicity is approximately $10-33 \%$. Detailed studies of induced seismicity via double-difference relocation and focal mechanism analysis have revealed a series of linear fault segments, none of which correspond to previously mapped faults. Yet, the remarkable coherence in their orientation suggests these were preexisting, optimally oriented, and critically stressed. These fault orientations reveal a consistent regional stress field that only varies over a narrow azimuthal range from $\sim 50^{\circ}$ to $74^{\circ}$. The strongest observed seismic events in Ohio appear to occur in the Precambrian basement and indicate that these rocks have the maturity needed to produce $M>2$ earthquakes and hence the greater potential hazard.
\end{abstract}

Keywords Induced seismicity $\cdot$ Hydraulic fracturing $\cdot$ Wastewater disposal $\cdot$ Appalachian Basin $\cdot$ Regional stress $\cdot$ Ohio

\section{Introduction}

An intensified extraction of unconventional gas and advanced technologies of underground fluid injection related to that process has caused a dramatic increase in the number of earthquakes in USA and Canada in the past decade (Ellsworth 2013; McGarr et al. 2015; Weingarten et al. 2015). Most of the seismicity contributing to that increase has

Maria Kozłowska

mkozlow@igf.edu.pl

1 Department of Geology and Environmental Earth Science, Miami University, Oxford, OH 45056, USA

2 Department of Seismology, Institute of Geophysics Polish Academy of Sciences, Warsaw, Poland been induced by wastewater disposal (WD) - the process of underground injection of water that flows back after hydraulic fracturing (HF), although some wastewater is simply produced from wells that have not had HF treatment (Walsh and Zoback 2015). HF itself is also responsible for inducing seismicity, but the maximum observed magnitudes ( $M$ 4.6) are currently lower than that of WD-induced earthquakes (M 5.9) (e.g., Holland 2013; Friberg et al. 2014; Skoumal et al. 2015c; Atkinson et al. 2016; Bao and Eaton 2016; Chen et al. 2017).

The most pronounced increase in the number of induced earthquakes in North America was observed in central and southern USA-Oklahoma, southern Kansas, and Texas, where Barnett and Woodford shale plays have been the target of operation and where wastewater has been disposed into 
the Arbuckle and Ellenburger formations overlaying crystalline basement (Frohlich et al. 2011; Holland 2013; Keranen et al. 2013, 2014; Walsh and Zoback 2015; Schoenball and Ellsworth 2017). Other areas of recent seismicity induced by WD and HF include Colorado, Arkansas, Ohio, Pennsylvania, West Virginia, New Mexico, Wyoming, Illinois in the USA as well as Alberta and British Columbia in Canada (e.g., Schultz et al. 2018; Skoumal et al. 2018; Kozłowska et al. 2018; Snee and Zoback 2018).

In this paper, we review the recent induced seismicity in the Appalachian Basin, where both WD and HF are being performed and have been shown to induce seismicity (Fig. 1). The Appalachian Basin extends from New York state in the north to Alabama in the south, along the inland side of the Appalachian Mountains. It is a foreland basin built of sedimentary Paleozoic rocks hosting coal, oil, and natural gas deposits. Coal has been mined in Appalachian Basin already for three centuries, whereas oil and gas have been discovered in 19th century and exploited since then. However, gas production in Appalachian Basin radically changed beginning in 2005, when horizontal drilling and HF were first performed in Pennsylvania targeting the unconventional Marcellus Shale. Targeting and production from the Marcellus spread to comparable areas of West Virginia, but the Marcellus shallows and thins considerably in eastern

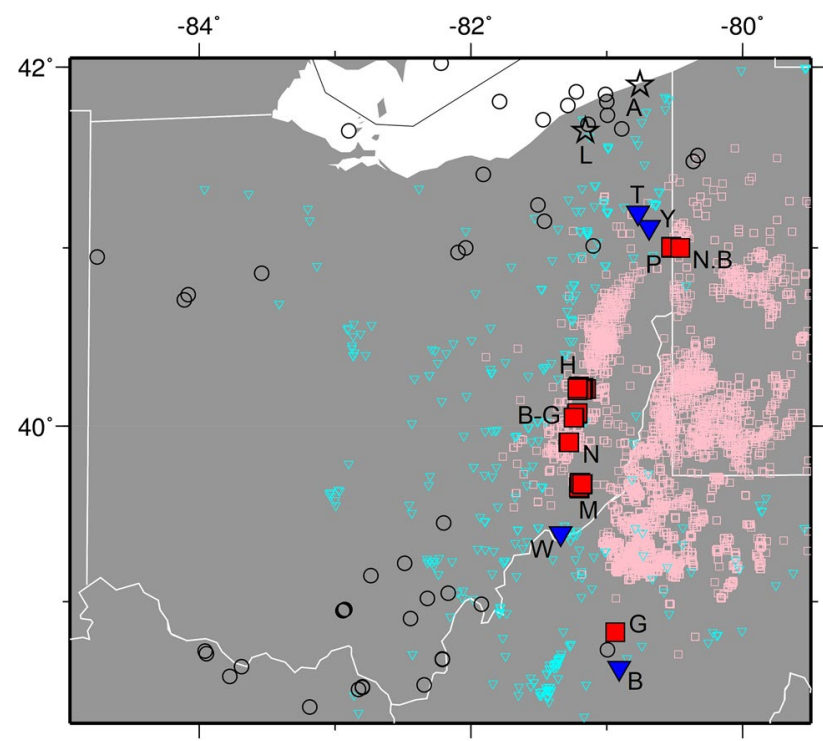

Fig. 1 Map showing the location sequences of cataloged $(M>\sim 2)$ seismicity in Ohio and neighboring states from 2010-2017. Blue triangles show sequences induced by WD, red squares-HF, pink squares, and cyan triangles show all horizontal and WD wells in the area (Ohio Department of Natural Resources-ODNR 2018c). Circles are earthquakes of probably natural origin. Stars mark earthquakes that may have been induced in the $1980 \mathrm{~s}$. Labels are A: Ashtabula, B: Braxton, B-G: Belmont-Guernsey, G: Gilmer, H: Harrison, L: Lake, M: Monroe, N: Noble, N.B: North Beaver, P: Poland, $\mathrm{T}$ : Trumbull, W: Washington, and Y: Youngstown
Ohio. With advances in technology, the deeper Utica-Point Pleasant Shale became economically viable in eastern Ohio and operators began drilling and HF this target in 2011.

Pennsylvania and West Virginia have been producing natural gas from Marcellus shale play using classical vertical wells for years; however, since 2009, the number of horizontal wells stimulated has rapidly increased creating the need to dispose of large volumes of wastewater (EIA 2018b). Due to the limited disposal capabilities in Pennsylvania (nine disposal wells with low storage capacity), most of the wastewater has been trucked to Ohio, where it was injected underground into Cambrian, Ordovician, and Silurian dolomites and sandstones (Kim 2013; Skoumal et al. 2014, 2015b, c; Holtkamp et al. 2015). At that time, the number of horizontal drilling permits in Ohio was low, but $\sim 2800$ permits were issued for Utica-Point Pleasant shale plays drillings between 2011 and mid-2018 (Ohio Department of Natural Resources (ODNR) ODNR 2018b). In the fourth quarter of 2017 alone, 1869 wells in Ohio produced over 14 billion $\mathrm{m}^{3}$ of gas (ODNR 2018c) making Ohio the fifth largest gasproducing state in the USA in 2017 after being nineteenth in 2012 (EIA 2018b). As a whole, the dramatic increase in production in the Appalachian Basin makes it currently the largest natural gas producer in the USA (EIA 2018a).

Historically, Ohio, Pennsylvania, and West Virginia have had a low level of natural seismicity, with approximately three cataloged $(M \geq 2)$ earthquakes per year from 1970 to 2009 during modern network recording (Fig. 2). Much of this weak activity has been concentrated near the shore of Lake Erie and along the Rome Trough that follows the border between Ohio and West Virginia (Hansen and Ruff 2003) (Fig. 1). However, this activity included a $M 5.0$ earthquake in 1986 near Perry, OH (Nicholson et al. 1988), which marked the beginning of a two-decade-long increased seismicity rate in Ohio (Fig. 2) that will be discussed in "Potentially induced seismicity in 1986-2006" section. Seismicity in Ohio then rises to even higher rates from 2010 to

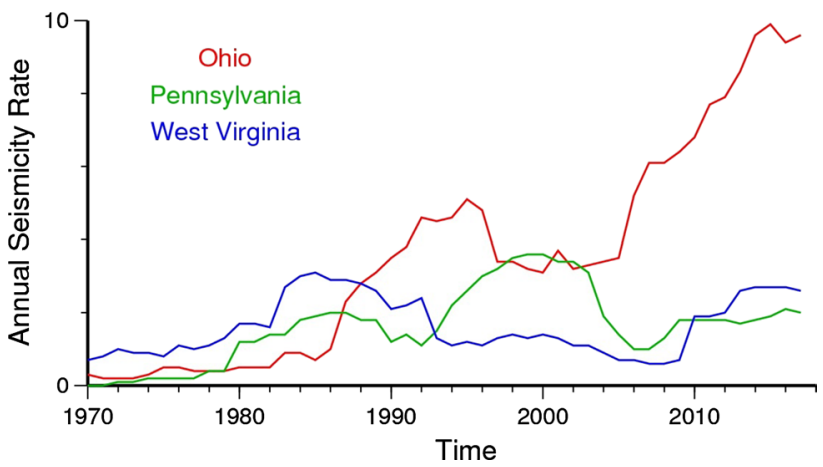

Fig. 2 Number of all cataloged $(M>\sim 2)$ earthquakes per year in Ohio, Pennsylvania, and West Virginia, averaged over the 10 prior years. This includes both natural and induced seismicity 
the present, including a $M 4.0$ near the city of Youngstown. This seismicity rate increase was suspected to be associated with an increase in WD and HF activities, and the strategies and seismic stations used to discern between natural and induced seismicity are reviewed in "Seismic monitoring and detection of induced earthquakes in the Appalachian Basin" section. Although Pennsylvania and West Virginia have not seen similar large increases in seismicity rates, there have been a few cases of induced seismicity in the past decade. The specific cases across the Appalachian Basin that demonstrate the relationships between seismicity and operational activities are described in detail in "Documented episodes of seismicity induced by WD" and "Documented episodes of seismicity induced by HF" sections. While this is primarily a review of previous studies, we have performed some comparable analyses on the most recent sequences and applied a uniform processing strategy to compare frequency-magnitude distributions across the various cases. We then provide some geologic interpretations of induced seismicity in the Appalachian Basin in "Interpretation" section.

\section{Potentially induced seismicity in 1986-2006}

Previous studies have identified three earthquake sequences in the Appalachian Basin prior to 2010 as potentially induced: 1986 in Lake County, 1987 in Ashtabula County, and 2000-2003 again in Ashtabula County, all in northeast Ohio (Fig. 1) (Nicholson et al. 1988; Seeber and Armbruster 1993; Seeber et al. 2004; Gerrish and Nieto 2005). The potential relationship of these events to injection activities has reached mixed conclusions, so we will reexamine the available evidence in this section.

To provide some context for interpreting the presence of previous seismic activity, northeastern Ohio had a history of 30 earthquakes prior to the 1986 sequence dating back to the $1800 \mathrm{~s}$, which suggests this area is prone to natural seismicity (Nicholson et al. 1988). The seismicity correlates with the prominent Akron magnetic lineament, likely reflecting different lithologies in the Precambrian basement, and a first-order structural boundary interpreted from reflection data (Seeber and Armbruster 1993). Of these 30 prior events, 3 occurred close to the 1986 Lake County sequence: a body wave magnitude (mb) 4.5-4.7 earthquake in 1943 $13 \mathrm{~km}$ west of the 1986 event, and two small events (mbLg 2.7 and 2.5) on January 22 and November 19, 1983, less than $5 \mathrm{~km}$ from one of the injection wells. The events in 1983 occurred about $30 \mathrm{~km}$ from the 1987 and 2000-2003 Ashtabula County sequences, but there are no other known earthquakes within $30 \mathrm{~km}$ prior to 1987. Seismicity has continued in Lake and Ashtabula Counties since 2010 (Fig. 1), but detailed analysis of recent earthquakes found the seismicity did not occur as long swarms and epicenters were greater than $10 \mathrm{~km}$ from active wastewater disposal wells and the older wells suspected to have induced seismicity in the $1980 \mathrm{~s}$ (Skoumal et al. 2015c). These findings were interpreted as evidence the Akron lineament represents a deep fault zone that has continued to host recent small earthquakes of the same natural origin as those prior to 1986.

On January 31, 1986, a mb 5.0 earthquake occurred near the southern border of Lake County followed by 13 aftershocks of duration magnitude (Md) 0.5-2.5 on February 1-March 24, 1986 (Nicholson et al. 1988), with an additional mb 2.8 aftershock on December 28, 1988. Two basement-penetrating Class I nonhazardous waste disposal wells $\sim 12 \mathrm{~km}$ from the sequence began full-scale injection in 1975 and 1981 into the basal Mt. Simon (1836 m) and Conasauga (1720 m) formations (Nicholson et al. 1988). Injection up to $\sim 636 \mathrm{~m}^{3} /$ day and $\sim 11 \mathrm{MPa}$ at these wells was suggested to have induced the events 5-11 years later when the effects of injection reached the fault (Nicholson et al. 1988). Nicholson et al. (1988) estimated the critical stresses needed to induce fault slip and concluded that without fluid injection, the conditions were near, but did not exceed, the necessary stresses to produce failure. However, the modeled pressure increase at the hypocenter was likely less than $0.34 \mathrm{MPa}$. Injection continued until the wells were plugged in 2004, but the seismicity was quiescent in this area after the initial sequence with only a mb 2.0 earthquake in 2003 $\sim 5 \mathrm{~km}$ to the east, and a mb 2.3 earthquake in $2006 \sim 8 \mathrm{~km}$ to the northwest. Fischer (1990) noted that this pattern of seismic activity is atypical of other sequences of allegedly induced earthquakes. While this event is now generally considered to be natural, the influence of the injection wells cannot be ruled out.

In July 1987, a separate sequence of 36 earthquakes, mbLg $-1.1-3.8$, occurred in Ashtabula County, $\sim 45 \mathrm{~km}$ northeast of the 1986 sequence (Fig. 1). These events outlined a $1.5-\mathrm{km}$ fault $<1 \mathrm{~km}$ from an injection well drilled into the basal Mt. Simon (1792 m) and Conasauga (1667 m) formations that began operation approximately a year earlier (Seeber and Armbruster 1993). The waste disposal well was plugged in 1994, and there was an average of one felt earthquake per year between 1987 and 2003 (Seeber et al. 2004). Intriguingly, earthquake sequences occurred again in 2000-2001 and 2003 about $5 \mathrm{~km}$ from the well and included a mb 4.3 event. The initial 1987 earthquake sequence was labeled as induced given the close proximity in space and time to the injection well operations (Seeber and Armbruster 1993), and a later study attributed the 2000-2003 seismicity to the migration of high pore-fluid pressures from the WD well (Seeber et al. 2004). However, pore-pressure modeling for the full Ashtabula seismic sequence by Gerrish and Nieto (2005) found no correlation between injection rates or pressures and the timing of the earthquakes. Instead, the seismicity follows a traditional mainshock-aftershock pattern 
common to natural earthquakes with the largest magnitude occurring first and the seismicity rate decreasing with time after the initial event. This lacks the swarm-like patterns common to induced sequences such as those at Rocky Mountain Arsenal (Healy et al. 1968), where there are typically a few events near the largest magnitude later in the sequence, and the seismicity rate is stable or even increasing with time. Gerrish and Nieto (2005) argued that while Coulomb failure theory cannot rule out triggering of the initial mainshock by the injection operations, the probabilities of shear failure due to effective stresses at the hypocenter are low. Moreover, the same authors noted that there is even less evidence for injection to be inducing new earthquake sequences several kilometers away over 5 years later. Instead, they pointed to the historical seismicity along the southern coast of Lake Erie and that the focal mechanism was consistent with tensile failure of basement lithologies along vertical fractures oriented parallel to the major principal regional stress field.

\section{Seismic monitoring and detection of induced earthquakes in the Appalachian Basin}

Due to the low level of natural seismicity, Ohio did not have a state-sponsored continuous seismic monitoring network. In 1999, the Ohio Seismic Network (OhioSeis) was established and consisted initially of 15 , and later even 29 vertical-component mid-period seismometers located primarily at colleges and universities across the state which expressed their willingness in hosting the station as part of their geology outreach (Hansen and Ruff 2003). As a result, the distribution of stations was not uniform. Today, the OhioSeis is operated by ODNR and includes 11 permanent broadband stations. Four stations were originally deployed as part of USArray in 2012 and 2013 under the EarthScope project. They were adopted by ODNR and are now used to monitor seismicity in eastern Ohio. Another ten former USArray stations are still operating in Ohio as a part of Central and Eastern U.S. Network (CEUSN). West Virginia does not operate a state-wide seismic network, but has also benefited from seven former USArray stations operating as part of the CEUSN.

The Pennsylvania State Seismic Network began in 2006 through a partnership between Pennsylvania State University and the Pennsylvania Department of Conservation and Natural Resources (DCNR). Between 2006 and 2013, the network grew to a total of ten seismic stations spread across the state providing near real time, open access data (Homman 2015). Prior to the arrival of the USArray Transportable Array in 2012, Pennsylvania pre-adopted several stations that were critical for monitoring several early cases of induced seismicity (Skoumal et al. 2014, 2015c). Between
2015 and 2016, an expansion of the network to 30 seismic stations began with funding from the DCNR and the Pennsylvania Department of Environmental Protection.

The initial detection and location of induced seismicity in Ohio have typically been accomplished by ODNR using the existing stations at the time. However, the lack of shortperiod local stations limited the detection and location of weaker events during early sequences. For example, after detecting a few earthquakes in Youngstown close to a disposal well, ODNR and Lamont-Doherty Earth Observatory deployed a local network in late 2011 to monitor the seismicity in the area (Kim 2013, Section 4.1). Similarly, local short-period stations were deployed temporarily by ODNR around WD and HF wells of interest ("Washington County, Ohio" and "Harrison County, Ohio" sections). Miami University contributed to observations of induced seismicity in the area by deploying additional broadband stations in Harrison, Guernsey, Belmont, Noble, and Monroe Counties, starting in October 2014. A few WD and HF operators have installed their own dedicated seismic networks in the area of operations, but those data are usually not available to the public ("Trumbull County, Ohio" vs. "Belmont/Guernsey/Noble Counties, Ohio" and "Monroe County, Ohio" sections).

ODNR currently utilizes the existing stations to perform earthquake detection and location via an Earthworm system to generate its catalog. To perform more in-depth analyses of recent seismicity, the detection process has been enhanced via template matching and repeating signal detector (RSD) (Kim 2013; Friberg et al. 2014; Skoumal et al. 2014, 2016). Both tools are based on seismic signal similarities expressed in the form of correlation coefficients (CC). In the template matching procedure, one or a few relatively strong and well recorded events are chosen as templates and used to scan through continuous waveforms from the same stations, searching for signals that produce high CC. RSD creates templates by using a clustering algorithm to identify groups of similar events based on comparisons in the time and frequency domains. Template matching and RSD have been effective in lowering the detection level 2 to 3 orders of magnitude compared to the ODNR-based catalog with simultaneous low numbers of false detections (Skoumal et al. 2014; 2016). Both procedures determine the local magnitudes of detected events using a Richter scale approach. For a few of the most recent cases ("Belmont/Guernsey/Noble Counties, Ohio," "Monroe County, Ohio" sections), we have applied template matching and/or RSD using the methods of Skoumal et al. $(2014,2016)$ to compare these sequences with previous cases.

The Gutenberg-Richter frequency magnitude distributions (FMD) (Gutenberg and Richter 1944) were typically calculated following the maximum-likelihood estimation or the least-squares linear approach. Although this is primarily 
a review paper, we sought to compare the nature of the FMD for the various cases discussed in this study, so we have applied a uniform maximum-likelihood estimation of the $b$ value to all cases using the catalogs from previous studies (Bender 1983) (Fig. 3). In some cases, we found that a truncated Gutenberg-Richter estimation using the equation of Caputo (1976) provided a better fit to the observed distribution. In all cases, we determined the $M_{C}$ using the maximum curvature algorithm (Wiemer and Wyss 2000).

The HypoDD double-difference algorithm (Waldhauser and Ellsworth 2000) was applied to relocate most of the induced sequences discussed in "Documented episodes of seismicity induced by WD" and "Documented episodes of seismicity induced by HF" sections (Skoumal et al. 2014, 2015a, b, 2018; Kozlowska et al. 2018). Each of these studies has used a 1D velocity model originally derived for eastern Ohio and adjusted to local conditions. The location uncertainties were typically determined using bootstrapping, and they depended on the number of stations available and their epicentral distance. In the case of Harrison Co and Trumbull Co where local stations were available, the absolute and relative location uncertainties were of the order of $100-150 \mathrm{~m}$ for both horizontal and vertical directions. In cases without a local network, the absolute location uncertainties were of the order of $1 \mathrm{~km}$ in the horizontal direction and potentially larger for the vertical direction.

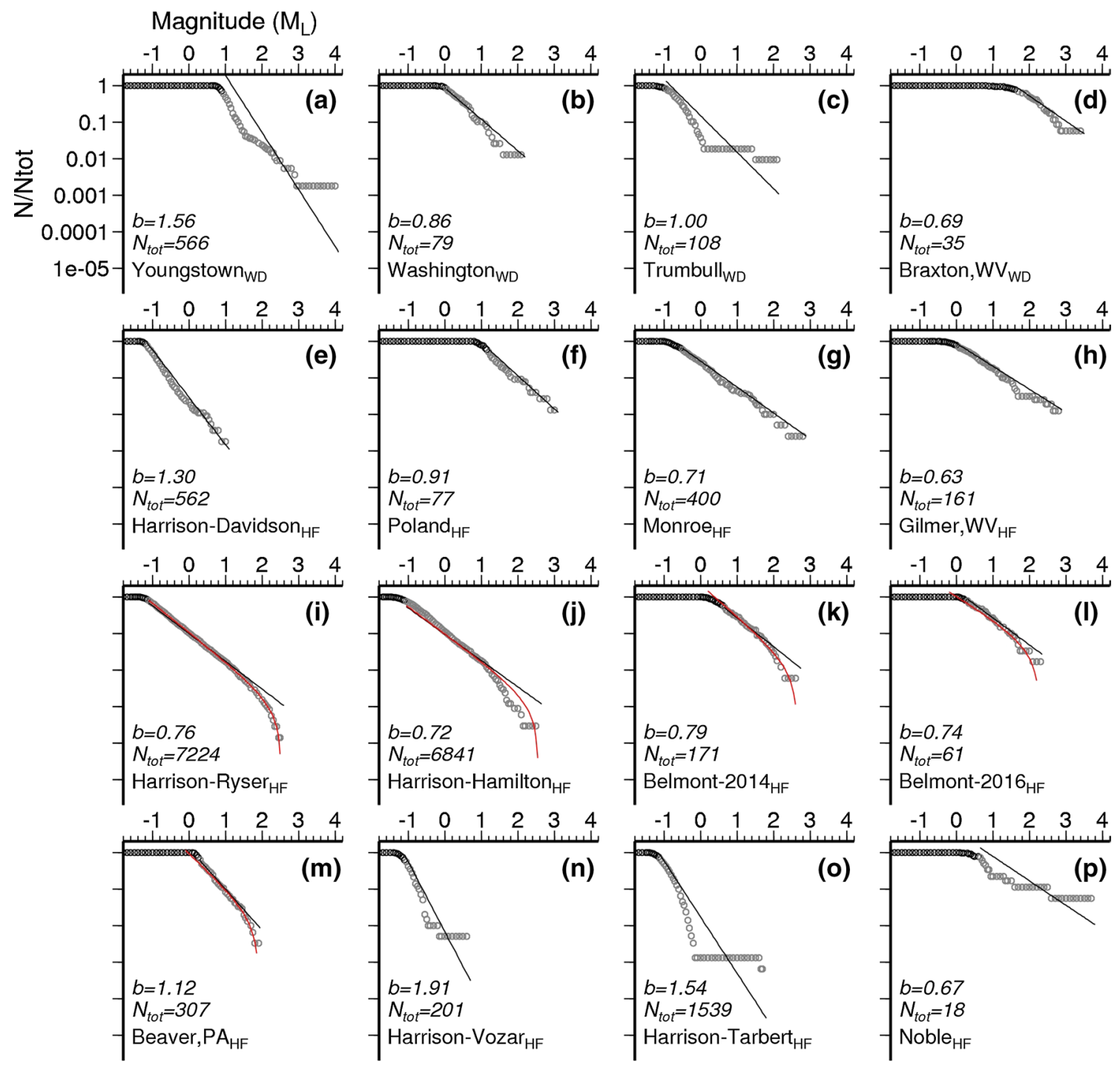

Fig. 3 Frequency-magnitude distributions of the various seismic sequences induced by WD and HF in the Appalachian Basin. $N / N_{\text {tot }}$ is the number of events at or above a given magnitude divided by the total number of events. The black circles are below the estimated Mc, and $b$ values were calculated using maximum-likelihood estimate.

The black line represents maximum-likelihood Gutenberg-Richter fit. Note that several cases $(\mathbf{a}, \mathbf{c}, \mathbf{n}, \mathbf{o}, \mathbf{p})$ do not appear to obey $\log -\log$ power law distribution and several other cases $(\mathbf{i}-\mathbf{m})$ are better fit by a truncated Gutenberg-Richter fit (red) 
Determination of whether seismicity was induced or natural followed the strategy of Skoumal et al. (2015c). The general approach to classifying induced seismicity has been to identify (1) an appropriate anthropogenic source that is potentially influencing the effective stress on a fault, (2) a correlation in timing of the human activity with the seismicity, and (3) a correlation in location between the potential source and the earthquake hypocenters (e.g., Davis and Frohlich 1993). The Skoumal et al. (2015c) study demonstrated that these criteria can be complemented by evidence for swarminess, where there are many events relative to the maximum magnitude observed, the largest magnitude event is not first, and there is a lack of aftershock decay pattern. Determining the presence or absence of swarm-like behavior can be aided by template matching. Figure 1 shows the results of classifying all cataloged events in the Appalachian Basin with this strategy.

\section{Documented episodes of seismicity induced by WD}

Only three seismic sequences in Ohio have been associated with WD (Fig. 1, Table 1) (Kim 2013; Skoumal et al. 2014; Skoumal et al. $2015 \mathrm{~b}, \mathrm{c}$ ), which means that $1.5 \%$ of the total number of active class II wells in Ohio (217-as of April 3 , 2018, ODNR 2018a) have induced seismicity that can be detected with current seismic monitoring technologies. For comparison, West Virginia has only had one WD well that induced seismicity (Skoumal et al. 2018), leading to a smaller percentage of WD wells associated with induced seismicity $(0.8 \%$, Table 1$)$. Pennsylvania has had no cases of WD-induced seismicity although this state has many fewer WD wells. While no state-wide traffic-light protocol is in place for WD, injection has been halted in Youngstown and Trumbull County, Ohio, and Braxton County, West
Virginia ("Youngstown, Ohio", "Trumbull County, Ohio," and "Braxton County, West Virginia").

\section{Youngstown, Ohio}

The largest magnitude sequence of induced seismicity in the Appalachian Basin in the past decade was identified when ODNR reported ten earthquakes of $M \sim 2$ close to Youngstown, starting from March 2011. Following a local deployment, the proximity of located earthquakes to an active class II well indicated the sequence was likely induced (Kim 2013). As a result, the injection was ceased on December 30, 2011; however, just a day later, the strongest $M 4.0$ event occurred less than $1 \mathrm{~km}$ from the well. Template matching revealed 566 similar, colocated seismic events, with the first event occurring 13 days after the injection began in December 2010 (Skoumal et al. 2014). The double-difference relocation of earthquakes showed the elongated cluster of seismicity trending ENE-WSW, starting $100 \mathrm{~m} \mathrm{SW}$ from the well (Fig. 4a). Earthquakes occurred at the depth between 3.5 and $4 \mathrm{~km}$, in Precambrian crystalline basement. Their spatiotemporal distribution showed that they migrated away from the well with time. The focal mechanism of the strongest event was consistent with the linear trend of the cluster indicating that the whole sequence occurred along near vertical, left-lateral basement fault.

Our estimation of the $b$ value for the whole sequence (1.56, Fig. 3a) is higher than that from a linear leastsquares fit (0.82), but Skoumal et al. (2015b) interpreted this is likely due to the sequence not following a log-log power law distribution. This could be due to FMD being quite different in earlier phases than later phases (Skoumal et al. 2014). The construction of a basement fault structure model and the estimation and simulation of pre- and postinjection stress state performed by Morris et al. (2017) contributed to understanding the inducing process of the
Table 1 Overview of injectioninduced seismicity in the three primary states of the Appalachian Basin operational activity

\begin{tabular}{lclcc}
\hline Region & $\begin{array}{l}\text { Wells with } \\
\text { earthquakes }\end{array}$ & $\begin{array}{l}\text { Wells with earth- } \\
\text { quakes (\%) }\end{array}$ & Total wells & $\begin{array}{c}\text { Maximum } \\
\text { magnitude }\end{array}$ \\
\hline Wastewater disposal wells & & & & \\
Ohio (All) & 3 & 1.5 & 127 & 4.0 \\
West Virginia (All) & 1 & 0.8 & 9 & 3.4 \\
Pennsylvania (All) & 0 & 0 & & - \\
Hydraulic fracturing wells & & & 1751 & 3.7 \\
Ohio (All) & 48 & 2.7 & 2148 & 2.7 \\
West Virginia (All) & 6 & 0.3 & 8706 & 1.9 \\
Pennsylvania (All) & 4 & 0.05 & 25 & 3.0 \\
Monroe Co. & 8 & 33 & 99 & 2.8 \\
Harrison Co. & 21 & 21 & 54 & 3.0 \\
Mahoning/Lawrence Co. & 9 & 17 & 140 & 3.7 \\
Noble/Guernsey/Belmont Co. & 14 & 10 &
\end{tabular}




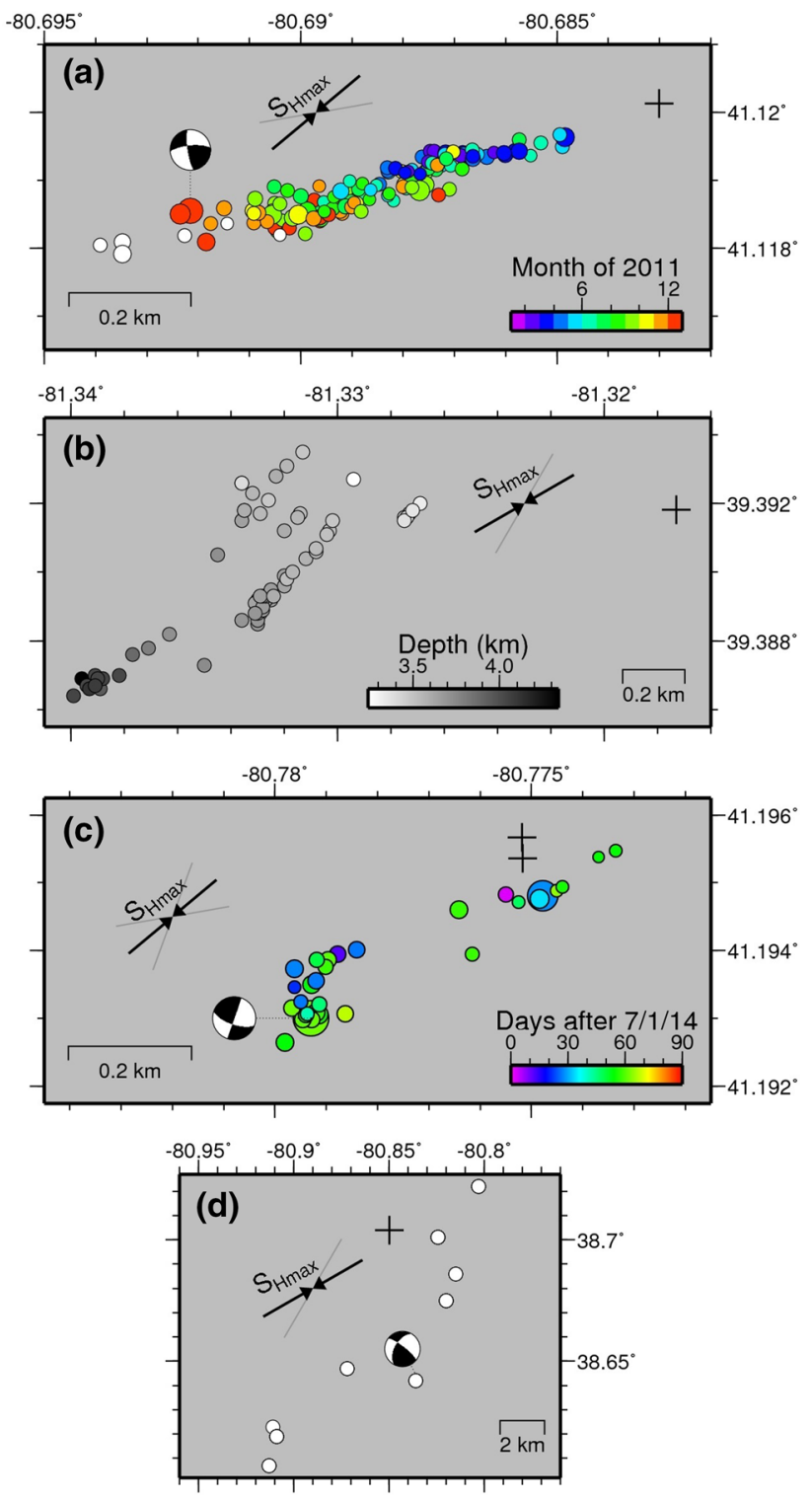

Fig. 4 Examples of clusters of WD-induced seismicity. Maps show the location of injection wells (cross) and earthquake locations (circles) for the a Youngstown, Ohio, b Trumbull Co., Ohio, c Washington Co., Ohio, and $\mathbf{d}$ Braxton Co., West Virginia. In (a-c), the refined double-difference relocations are shown, while in (d) only the catalog locations are available. In (a, b), the circles are scaled according to magnitude. Focal mechanisms are shown when available. The arrows show orientation of maximum horizontal stress, and the gray lines are the fault orientation suggested by focal mechanism and trend of hypocenters

Youngstown sequence. Their comparison of reported injection pressures and simulated pore-pressure perturbations within the basement indicated that permeability anisotropy was needed to perturb pore pressures enough to induce fault reactivation. In particular, the combination of low-permeability basement host rock and highpermeability fault zone amplified the pore-fluid pressure perturbation and increased the likelihood of fault reactivation given the fault zone was appropriately oriented. The effective permeability of the injection interval increased in the downward direction as injection progressed leading to a larger, connected fault area, culminating in the large slip of $M 4.0$ event.

\section{Washington County, Ohio}

The first recorded seismic event in Washington County occurred in October 2010 and had a magnitude of 2.8 (Skoumal et al. 2015c). Just 2 weeks after the event, the EarthScope TA stations were deployed in western Pennsylvania and they were used for template matching on subsequent events. The procedure revealed a pattern of ongoing seismicity with over 100 events detected between 2011 and 2013 . The strongest event in the sequence occurred in August 2011 and was of magnitude 3.1. The location of five template events showed that they were all located close to each other, less than $2 \mathrm{~km}$ from WD well which started injection in September 2008. The FMD of this sequence has a relatively low $b$ value $(0.86$, Fig. $3 \mathrm{~b})$, but there are indications of a divergence from the expected log-log power law distribution as seen in the Youngstown case.

In 2013, ODNR deployed a local network of five stations in the area of observed seismicity. Currie et al. (2018) analyzed their data between May 2013 and July 2015 and performed multi-station template matching identifying over 300 events down to magnitude -0.7 . The double-difference relocation of these events with the local network (Fig. 4b) showed they were close to the earlier events analyzed in the previous study but closer to the injection well. The relocated hypocentral depths correspond to lower Cambrian and upper Precambrian strata, reported by Baranoski (2013). The epicenters formed elongated cluster with NE-SW trend that Currie et al. (2018) also found parallels the trend of small-amplitude folds in Upper Paleozoic rocks and is optimally oriented within the regional stress field. Hypocentral patterns and similar structures imaged in nearby seismic reflection lines indicate the seismicity occurred on a positive flower structure initiating in the basement and separating into braided segments in the sedimentary layers. These basement-involved fault systems cut the injection interval targeted by the WD well, providing permeability pathways for fluid pressure increases that would promote seismic slip. Well completion records indicate the nearby WD well was injecting fluids close to or above the fracture pressure of the targeted Silurian interval. As expected, seismicity rates followed the monthly injection rates during the studied time frame. Taken together, Currie et al. (2018) concluded the seismicity was the result of pore-pressure change caused by WD, similar to the Youngstown sequence. 


\section{Trumbull County, Ohio}

The first earthquake in Trumbull County was reported by ODNR and U.S. Geological Survey in August 2014. The ML 2.1 event was located within $1 \mathrm{~km}$ of two class II wells, the shallower one injecting water into Silurian strata and the deeper one into sediments $\sim 15 \mathrm{~m}$ above the Precambrian basement (Skoumal et al. 2015b). Following the event, ODNR ordered the suspension of operations at both wells, but 2 weeks later, the operation was resumed at the shallower well after the investigation stated that it did not influence the occurrence of the ML 2.1 earthquake. Template matching was performed for both regional and local data-the operator deployed a temporal network of four short-period stations within $4 \mathrm{~km}$ from the wells. The procedure identified over 100 events in the 3 months leading up to the shutdown. Double-difference relocation earthquakes formed two clusters (Fig. 4c), one adjacent to the deeper well and the second $\sim 400 \mathrm{~m}$ southwest and few hundred meters below the bottom of the well, in the Precambrian basement. The clusters differed also in their spatial distribution-the proximal one had a ENE-WSW trend similar to the Youngstown sequence, whereas the distal one that formed later followed a NNE-SSW trend (Skoumal et al. 2015b). The distal cluster also included the ML 2.1 event, for which a fault-plane solution revealed a strike-slip mechanism with the north-south fault plane aligning with the trend of hypocenters. Despite the different azimuths, both observed trends of seismicity in Trumbull County are optimally oriented relatively to the NE-SW orientation of the maximum horizontal stress SHmax (Hurd and Zoback 2012). The rate of seismicity in the area dramatically decreased after the injection was halted at both wells, and it has not yet returned after the shallow well was resumed, indicating a correlation to the deep well injection.

The $b$ value for Trumbull County seismicity is essentially 1 (1.00, this study; 0.91, Skoumal et al. 2015b), but the initial study noted that the FMD does not follow a power law due to a few much larger events and suggested a different relationship is at work. This observation, along with lack of aftershock productivity and narrow magnitude range, is predicted by numerical simulations of a seismogenic zone governed by a viscoelastic damage rheology when the viscosity in the fault zone is reduced (Ben-Zion and Lyakhovsky 2006). Such a reduction in viscosity is expected if deep WD increases fluid pressures in the fault zone to the point that the fault zone begins to dilate.

\section{Braxton County, West Virginia}

Seismicity in Braxton County began with a series of eight earthquakes between April and July 2010 within a few kilometers of an active wastewater injection well (Fig. 4d), including a $M 3.4$ event. The West Virginia Department of Environmental Protection (WVDEP) reduced the injection rate at this well soon after these events began, and WVDEP further restricted both the volume and the rate after an additional $M 2.8$ earthquake occurred in January 2012. The well was shut-in at the end of 2013 after another M 3.4 event occurred in March 2013. Template matching utilizing existing stations in the region over this time frame grew the catalog of detected events to 54 (Skoumal et al. 2018), revealing a distinct decrease in seismicity rate once the rate and volume reductions were enacted, which was not visible with the NEIC catalog alone. Although double-difference relocations have not yet been performed on this sequence, the catalog locations appear to follow a northeast-southwest trend that parallels a fault plane from the focal mechanism of the largest event (Fig. 4d). The Rome Trough Eastern Margin Fault appears to occur in the vicinity of the well and follow a similar orientation, with structural evidence that the fault cuts the injection interval (MRCSP 2009; McDowell et al. 2014). The FMD of this sequence is similar to that of Washington Co., Ohio, that occurs on the western margin of the Rome Trough (Fig. 1). The $b$ value is relatively low (0.69), but there are indications of a divergence from the expected log-log power law distribution as seen in the other WD cases.

\section{Documented episodes of seismicity induced by HF}

In this section, we show a review of cases of seismicity induced by HF in Ohio which is important for understanding the relationship between seismicity and operational activities. Table 1 summarizes the HF-induced seismicity in the Appalachian Basin, with most cases occurring in Ohio and growing in prevalence since 2012. Increases in oil and gas production and rising seismic hazard led to introducing state regulations concerning seismic monitoring and traffic-light system for HF wells operations. HF operators are required to monitor potential seismicity if the permitted well is located within 3 miles $(\sim 3.8 \mathrm{~km})$ from known fault or previous seismicity (ODNR 2017a). The ODNR regulations require direct communication between the operator and Division of Oil and Gas Resources if a local magnitude ML 1.5 or higher event occurs during operation, modification of operation if ML 2.0-2.4 event occurs, temporal halt of operation if ML 2.5 or higher event occurs, and suspension of the whole pad completion until an approved plan is submitted by operator if ML 3.0 or higher event occurs. As far as we know, these regulations or earlier forms of them have been employed to halt completion operations at wells in Poland Township and Noble County cases ("Poland Township, Ohio and North 
Beaver Township, Pennsylvania" and "Belmont/Guernsey/ Noble Counties, Ohio" section).

\section{Harrison County, Ohio}

The induced seismicity occurring in Harrison County has formed a series of seismic sequences from 2013 to 2017 (Friberg et al. 2014; Skoumal et al. 2015c; Kozłowska et al. 2018). Seismicity in Harrison County was caused by HF performed on nine well pads in the southern part of the county (Fig. 5a). The first earthquake in the area was recorded in October 2013 by USArray stations operating in eastern Ohio. By November 2013, ODNR deployed four portable short-period stations close to the epicenters of recorded events. The initial sequence lasted until the end of 2013 (Fig. 5b) and was located directly below the Ryser wells (Friberg et al. 2014). In the following years, another five well pads induced productive seismic sequences
Fig. 5 Examples of clusters of HF-induced seismicity. (a) Map of the Harrison County region showing HF well pads (circles), earthquakes (crosses), and county lines (lines). HF wells and earthquakes are colored if they were associated. Focal mechanisms are shown when available. (b) Enhanced seismicity catalog for the Harrison Co. region. Colors mark cases where earthquakes correlate in space and time with HF wells. Reported/estimated HF times are shown as thin bars across the top. Other maps and timelines are for the (c, d) Poland Twp., $\mathrm{OH}$, and Lawrence Co., PA, (e, f) Noble/ Belmont/Guernsey Co., and (g, h) Monroe Co. regions
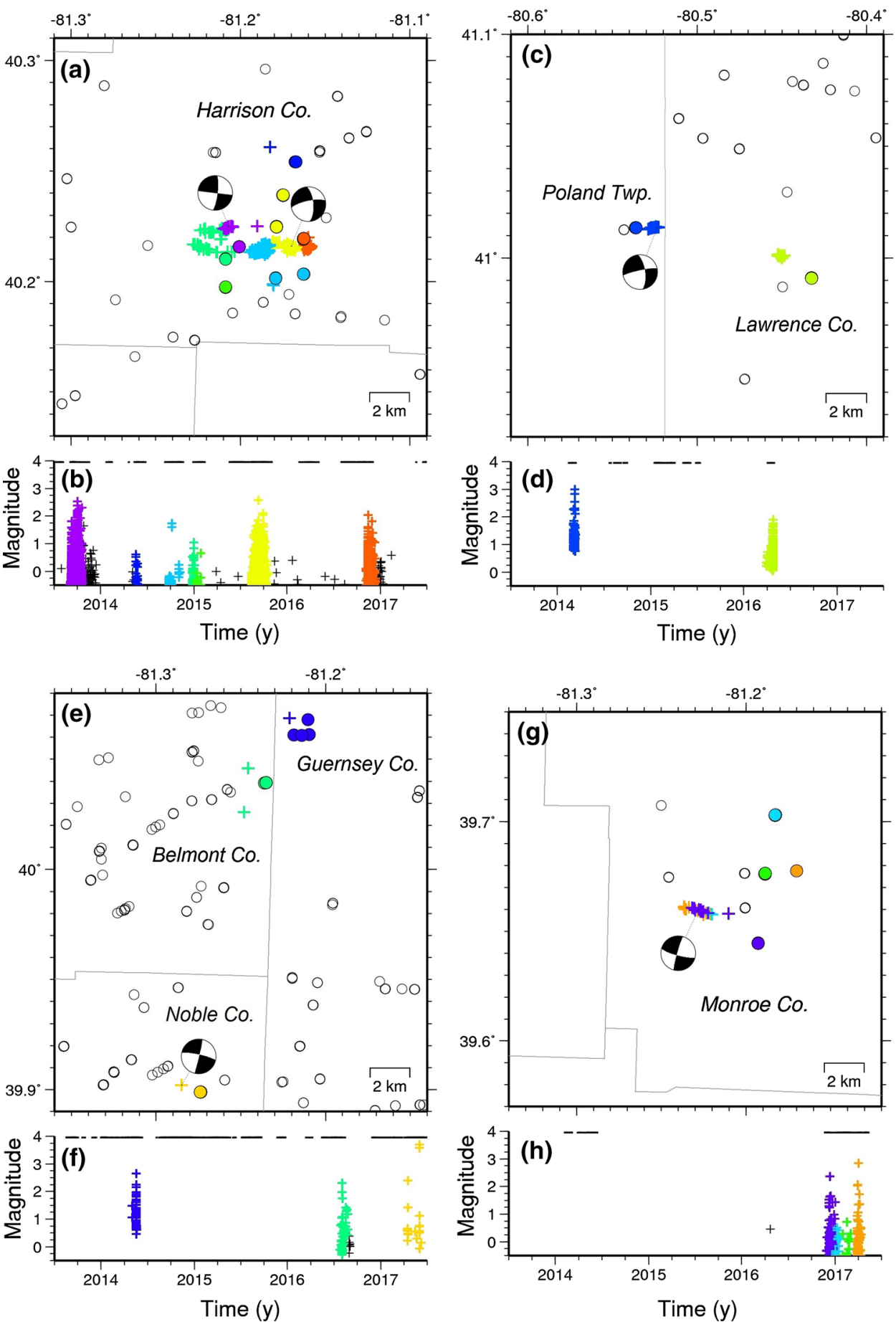
(> 500 detected events) in an area of only $\sim 5 \mathrm{~km}$ length and $\sim 2 \mathrm{~km}$ width. Utilizing recordings from an EarthScope station located only a few kilometers north of the HF wells, a repeating seismicity detection procedure utilizing agglomerative clustering of frequency and time domain signals was able to identify over 13,000 seismic events from the beginning of 2013 until the end of 2015 (Skoumal et al. 2016). An additional sequence associated with the Conotton well pad stimulated in November 2016 was also detected, but detailed analysis of this sequence is currently in progress (Friberg et al. 2018). Despite all of this seismicity, magnitudes have not exceeded ML 2.8. Hence, HF operations have generally continued without interruption, although activities on the Hamilton and Conotton pads were adjusted and/or temporarily paused (ODNR, pers. comm.).

Table 1 summarizes the prevalence of HF-induced seismicity in the southwestern area of Harrison County shown in Fig. 5a by taking the number of HF wells that have induced magnitude $>1$ seismicity (21) divided by the total number of HF wells in a 20-km-wide box that encloses the area where induced seismicity has occurred (99). The resulting percentage $(21 \%)$ is an order of magnitude higher than the percentage we obtain for the whole state of Ohio, indicating that certain areas of the state have a higher likelihood of induced seismicity than others. This issue is discussed in detail in "Interpretation" section.

The double-difference relocation performed on the productive earthquake sequences between 2013 and 2015 showed that all induced events occurred at a small epicentral distance from the nearest recently active HF stage-less than $1 \mathrm{~km}$ (Kozłowska et al. 2018). The time lag between hydraulic stimulation and the seismic response was very short, approximately $120 \mathrm{~min}$, clearly indicating the inducing relationship. However, such a short response time compared with distance between HF and first seismic event would translate into an abnormally high value of hydraulic diffusivities. In this case, pore-pressure diffusion is not likely the primary factor inducing seismicity and poroelastic stress is a better candidate for the physical mechanism responsible for initiating the seismicity (Kozłowska et al. 2018). The horizontal distribution of located events shows quasi-linear trends consistent with east-west fault-plane solutions that are optimally oriented $30^{\circ}$ from SHmax (Kozłowska et al. 2018). The depth distribution of events, however, shows that seismicity observed in Harrison County occurred on two separated levels: (1) within Paleozoic sedimentary rocks about $400 \mathrm{~m}$ below the target interval and (2) about $600 \mathrm{~m}$ deeper than the first level in the Precambrian basement. Interestingly, sequences characterized by greater depth showed low $b$ value $(<1$; Fig. $3 \mathbf{i}-\mathbf{j})$, whereas sequences located in Paleozoic strata showed $b$ values much higher (generally $>1.5$; Fig. $3 n-0$ ). Interpreting these results in the context of recent laboratory work and the knowledge of local geology, Kozłowska et al. (2018) proposed the two observed types of seismicity represent the activation of a fault system originating in the Precambrian basement and continuing into Paleozoic strata. Due to the age and inferred difference in slip history, activated faults would differ in surface maturity leading to different FMD patterns: old, mature Precambrian faults have a smoother surface which would promote larger slip, and hence, larger magnitude seismic events than younger, less mature, and thus more rough Paleozoic faults. An investigation of the water and gas production data also revealed that wells inducing deeper seismicity produced more water than wells with shallow seismicity, indicating more extensive hydrologic connections outside the target formation.

\section{Poland Township, Ohio, and North Beaver Township, Pennsylvania}

A new sequence of seismicity reaching ML 3.0 appeared in Mahoning County in March 2014, but this time the seismicity was focused in Poland Township, $18 \mathrm{~km}$ southeast of the Youngstown sequence (Skoumal et al. 2015a). Although there were no local stations during this sequence, it was located within $1 \mathrm{~km}$ of an active HF well (Fig. 5c), and completion was suspended after the ML 3.0 event. Template matching was performed using regional data revealing 60 seismic events primarily occurring during six stages on two well laterals that were closest to the hypocentral locations, although a small amount of seismicity persisted for a few days after these stages. The location of the strongest of detected events showed that they formed an east-west band parallel to Youngstown seismicity and consistent with a fault-plane solution for the largest event (Fig. 5c). The sequence occurred $500 \mathrm{~m}$ below the target Utica-Point Pleasant formation at the top of the crystalline basement. We calculated a relatively low $b$ value of 0.91 (Fig. 3f), similar to the 0.89 estimated by Skoumal et al. (2015a) and consistent with the deeper cases of basement seismicity from Harrison County (Fig. 3i-j). The Poland Township FMD is also linear, but it does not appear to be truncated like some cases of Harrison County although those cases lasted significantly longer (several weeks to months).

Approximately 2 years later, seismicity began again in North Beaver Township, Pennsylvania, $\sim 6 \mathrm{~km}$ east from the Poland Township sequence (Fig. $5 \mathrm{c}-\mathrm{d}$ ). Template matching was performed using a template event reported by USGS and two regional TA stations (Skoumal et al. 2018). It revealed a seismic swarm with two main clusters temporally and spatially correlated with individual stages of HF performed at two well laterals being "zipper" stimulated (alternating stages between wells). Following the strongest ML 1.9 event, the operator voluntarily halted operations at the well and seismicity soon stopped. Relocation of the observed swarm 
showed that it formed an east-west trend, similar to the Poland Township cluster. Although the absolute depth of this sequence is poorly determined, the FMD is most similar to that of the deeper Harrison County wells (Fig. 3m). The wells in North Beaver Township targeted the Utica and Point Pleasant formations, which is rare in Pennsylvania, as nearly all other wells target the shallower Marcellus Shale. None of the wells targeting the Marcellus in Pennsylvania currently have documented induced seismicity (Skoumal et al. 2018). Table 1 summarizes the prevalence of induced seismicity associated with wells operated in the combined area of Mahoning and Lawrence Counties near the Ohio-Pennsylvania border. There are 45 well laterals without seismicity in this $20-\mathrm{km}$-wide box, indicating $17 \%$ of wells have induced seismicity, similar to what we calculated for southwest Harrison County.

\section{Belmont/Guernsey/Noble Counties, Ohio}

About $15 \mathrm{~km}$ south of the Harrison County seismicity, a sequence of five ML 2 earthquakes near the border of Belmont and Guernsey Counties was reported in May 2014 in EarthScope catalog (Skoumal et al. 2015c), with the strongest event reaching ML 2.6 (Fig. 5e, f). Due to poor station coverage, only the four largest events were located with large uncertainties $(\sim 1.5 \mathrm{~km})$; however, the location was near the active Kirkwood well pad targeting the Utica-Point Pleasant formation. The temporal analysis of events showed that they occurred during HF operations on two laterals being zipper stimulated, with the main cluster occurring during stimulation of eight consecutive stages with a trail of seismicity lasting for $\sim 3$ days after a pause in the operations. The $b$ value and FMD pattern were not reported by Skoumal et al. (2015c), so we have calculated this in Fig. 3k. The $b$ value (0.79) and truncated shape of the FMD are quite similar to the deeper Harrison County sequences.

Seismic activity occurred again in August 2016 about $3 \mathrm{~km}$ southwest of the first sequence when a M2.3 event was reported by ODNR (Fig. 5e, f). Although this sequence has not been studied in detail, we performed template matching with station O53A using the method of Skoumal et al. (2015c) and found 61 events over a month duration. This sequence coincides in space and time with activity at the Wheeler well pad targeting the Utica-Point Pleasant. Seismicity primarily occurred during zipper stimulation of the last $~ 12$ stages of two laterals $(7 \mathrm{H}$ and $9 \mathrm{H})$ that were closest to where the May 2014 seismicity occurred. Seismicity continued at a slower rate for over 3 weeks after the stimulation ended. The $b$ value (0.74) and truncated shape of the FMD are similar to the May 2014 sequence (Fig. 31).

Less than a year, later in June 2017, seismicity occurred $\sim 15 \mathrm{~km}$ south of the Belmont/Guernsey sequences in neighboring northeastern Noble County (Fig. 5e, f). Two events with ML 1.6 and 2.4 reported by ODNR and located directly below an active Wehr $2 \mathrm{H}$ horizontal well. Following those events, the completion of the well was suspended and no further seismicity was recorded during completion of nearby Slash wells until 6 weeks later, when ML 3.7 event occurred during the stimulation of the Wolf $2 \mathrm{H}$ well. This event is thus far the strongest HF-induced event in Ohio and was widely felt in the rural epicentral area-over 100 felt reports were submitted to USGS. Intriguingly, only 18 events were detected with template matching using the method of Skoumal et al. (2015c) and repeating signal detection using the method of Skoumal et al. (2016). Double-difference relocation has not been attempted on this sequence, but a focal mechanism shows an east-west fault plane similar to events in Harrison County (Fig. 5e) (ODNR 2017b). Given the small number of events detected in this sequence, it is difficult to calculate a $b$ value that is meaningful, but the FMD clearly shows a non-power law distribution (Fig. 3p) similar to the shallower Harrison County cases.

\section{Monroe County, Ohio}

Seismicity in southwestern Monroe County was first observed in December 2016 when three events with magnitudes 2.0-2.3 were reported by ODNR. These events correlated in space and time with HF activity on the Donato well pad (Fig. $5 \mathrm{~g}, \mathrm{~h}$ ), although the highest seismicity rate occurred immediately after a lateral finished. Two more magnitude 2.4 earthquakes were detected on March 30, 2017, followed by a magnitude 3.0 earthquake on April 2 . These events occurred in a similar location to those in 2016, although the HF wells operating at the time (Gary Green and Jacobs well pads) were a few kilometers further north (Fig. 5g). The strongest (3.0) event occurred right after flowback on the Donato well pad commenced (ODNR, pers. comm.), suggesting this process played a role. After enhancing the catalog of events using the template matching approach of Skoumal et al. (2015c), the $b$ value and linear FMD (Fig. 3g) resemble that of the post-HF seismicity associated with the deeper Harrison County well pads. No other seismicity has been detected in southwestern Monroe County, but only a handful of well pads have been stimulated in this area. Hence, the percentage of HF wells inducing seismicity (33\%) appears to be highest in this region (Table 1).

\section{Gilmer County, West Virginia}

A short sequence of seismicity occurred in Gilmer Co. between July and August 2013. Using five cataloged earthquakes that reached a magnitude of 2.7 , template matching was able to reveal 161 unique events (Skoumal et al. 2018). Seismicity began soon after HF started and ending soon after 
the last completion, with five laterals completed on this well pad that was $\sim 3 \mathrm{~km}$ from the cataloged epicenters. No other horizontal wells have been hydraulic fractured in this county of West Virginia, but the WD-induced seismicity in West Virginia occurred $\sim 20 \mathrm{~km}$ south in the neighboring Braxton Co. The $b$ value and FMD pattern were not reported by Skoumal et al. (2018), so we have calculated this in Fig. 3h. The $b$ value (0.63) and linear shape of the FMD resemble that of Monroe Co and the post-HF seismicity associated with the deeper Harrison County well pads.

\section{Interpretation}

Our review of induced seismicity in Ohio and surrounding regions highlights that the prevalence of induced seismicity varies a lot spatially, and in some localities, the prevalence is significantly higher than previously thought. At the state scale, we find that the prevalence of induced seismicity in Ohio is higher than West Virginia for both WD and HF, which in turn is higher than Pennsylvania for both. The explanation for this proposed by Skoumal et al. (2018) is that the distance between operations and the Precambrian basement where faults are expected to be more mature is quite a bit larger in Pennsylvania and West Virginia than Ohio. The area of West Virginia where induced seismicity is occurring is thought to be the southern edge of the Rome Trough and may represent an area where faulting is more pronounced and extends further up into the Paleozoic sedimentary rocks (Skoumal et al. 2018). An intriguing difference from previous studies is that Ohio now has a higher per-well prevalence for induced seismicity from HF than from WD. This is counter to the interpretation that WD has a higher likelihood of producing seismicity than HF due to longer duration injection and hence larger total volumes (e.g., Rubinstein and Mahani 2015). The best interpretation may be similar to that of Skoumal et al. (2018) in that most HF wells are injecting closer to basement than most WD wells. When we examine the regions of induced seismicity in further detail, we find that the prevalence of HF-induced seismicity over a $20 \times 20 \mathrm{~km}$ wide region can be even higher, with numbers ranging from 10 to $33 \%$. This suggests that local variability is important and still plays a big role in determining the risk of induced seismicity.

Despite the local variability in the prevalence of induced seismicity, there is remarkable coherence in the orientation of faults that have induced seismicity. Many of these sequences have created extensive sequences of similar events with nearby recordings to allow for double-difference relocations that reveal linear fault segments (Friberg et al. 2017; Skoumal et al. 2014, 2015a, b, 2018; Kozlowska et al. 2018; Currie et al. 2018). In addition, many of these sequences have produced a large enough event to determine focal mechanism (Kim 2013; Friberg et al. 2017; Skoumal et al. 2015a, b, 2018; Kozlowska et al. 2018). Remarkably, all of these fault orientations are $\sim 30^{\circ}$ from the expected direction of SHmax (Hurd and Zoback 2012). None of induced sequences occurred on a known, mapped fault, but the consistency suggests these were preexisting, optimally oriented, critically stressed faults. This is supported by the geomechanical modeling of the stress evolution in the Youngstown case that showed a preexisting fault needed to be in a critical stress state before the onset of seismicity in order for the modest increases in pore pressure associated with WD to cause seismic slip (Morris et al. 2017). Figure 5 shows the orientations of SHmax estimated by assuming a 30-degree offset from the fault orientations from recent HF and WDinduced seismicity, as well as the two older possible cases of injection-induced seismicity. This analysis reveals a consistent regional stress field that only varies over a narrow azimuthal range from $\sim 50^{\circ}$ to $74^{\circ}$ (Fig. 5). This trend is consistent across a nearly $400 \mathrm{~km}$ long north-south extent.

Finally, we turn our attention to the fact that induced seismicity has been essentially restricted to relatively narrow north-south corridor along eastern Ohio and into central West Virginia. One possibility is that this corridor represents a zone of more intense faulting during previous orogenies, but the lack of any prior natural seismicity in eastern Ohio (Skoumal et al. 2015c) argues against this idea. Another possibility is that it is simply due to the geography of operational activities, but there are just as many HF wells east and west of the seismicity corridor and just as many WD wells to the west (Fig. 1). However, the HF wells to the east of this corridor are generally targeting the Marcellus formation, which is significantly further from the basement rocks where the majority of the seismicity is occurring and appears to lower the prevalence of induced seismicity (Skoumal et al. 2018). Likewise, many of the WD wells to the west of the seismicity corridor target shallower formations that would lower the likelihood. So, we believe the leading hypothesis for the north-south corridor of seismicity is that the target depth of HF and WD operations in this corridor is closer to basement and leads to higher risk of induced seismicity in this zone (Fig. 6).

Finally, we note that most of the sequences with good depth resolution have occurred in Precambrian basement, where preexisting faults are thought to be mature enough to produce $M>2$ earthquakes. While there is geologic evidence that these faults would be mature based on the ages of these rocks and tectonic history of eastern North America, the low $b$ values of these deeper sequences correspond to those observed in laboratory measurements of mature fault surfaces (Goebel et al. 2017; Kozłowska et al. 2018). Recent induced earthquakes in the Appalachian Basin have reached a magnitude of 4.0 and 3.7 for WD and HF, respectively. We anticipate that operational activities could produce larger 


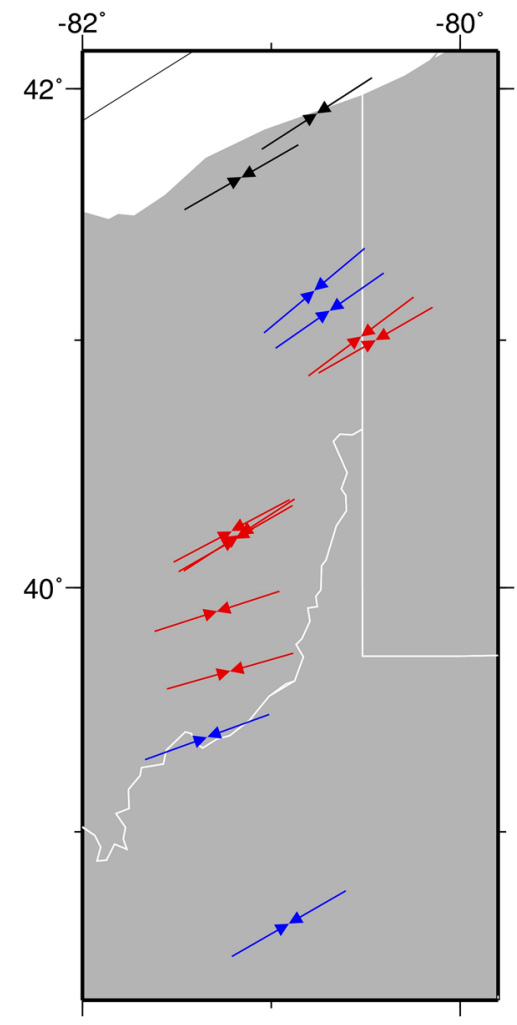

Fig. 6 Map of Eastern Ohio showing the apparent SHmax direction (arrows) determined using the focal mechanisms and relocated hypocenters from induced seismicity (both recent and the potentially induced older events): red $=\mathrm{HF}$, blue $=\mathrm{WD}$, and black $=$ old. Symbols are centered on the epicenter of the largest earthquake in the sequence

magnitude earthquakes considering that the magnitude 5.0 earthquake near Perry, OH, in 1986 is suspected of being induced by fluid injection and that other earthquakes in North America induced by WD and HF have reached magnitudes of 5.9 and 4.5 , respectively.

Acknowledgements This work has been conducted in the framework of the Shale Gas Exploration and Exploitation Induced Risks (SHEER) project funded by the European Union's Horizon 2020 Research and Innovation Programme under Grant Agreement No. 640896. Additional support was provided by US National Science Foundation Grant 1614942, US Geological Survey National Earthquake Hazards Reduction Program Grant G15AP00089, a Kosciuszko Foundation Grant, and the ODNR Geologic Survey.

OpenAccess This article is distributed under the terms of the Creative Commons Attribution 4.0 International License (http://creativeco mmons.org/licenses/by/4.0/), which permits unrestricted use, distribution, and reproduction in any medium, provided you give appropriate credit to the original author(s) and the source, provide a link to the Creative Commons license, and indicate if changes were made.

\section{References}

Atkinson GM, Eaton DW, Ghofrani H et al (2016) Hydraulic fracturing and seismicity in the western Canada sedimentary basin. Seismol Res Lett 87:631-647

Bao X, Eaton DW (2016) Fault activation by hydraulic fracturing in western Canada. Science 354:1406-1409

Baranoski MT (2013) Structure contour map on the Precambrian unconformity surface in Ohio and related basement features (version 2.0). Columbus, Ohio Department of Natural Resources, Division of Geological Survey Map PG-23, scale 1:500,000, 17

Bender B (1983) Maximum likelihood estimation of $b$ values for magnitude grouped data. Bull Seismol Soc Am 73:831-851

Ben-Zion Y, Lyakhovsky V (2006) Analysis of aftershocks in a lithospheric model with seismogenic zone governed by damage rheology. Geophys J Int 165:197-210

Caputo M (1976) Model and observed seismicity represented in a twodimensional space. Ann Geofis 29:277-288

Chen X, Nakata N, Pennington C et al (2017) The Pawnee earthquake as a result of the interplay among injection, faults and foreshocks. Sci Rep 7:4945. https://doi.org/10.1038/s41598-017-04992-z

Currie B, Free JM, Brudzinski MR, Leveridge M, Skoumal RJ (2018) Seismicity induced by wastewater injection in Washington County, Ohio: influence of preexisting structure, regional stress regime, and well operations. J Geophys Res. https://doi. org/10.1002/2017jb015297

Davis SD, Frohlich C (1993) Did (or will) fluid injection cause earthquakes?-Criteria for a rational assessment. Seismol Res Lett 64:207-224

EIA (2018a) U.S. energy information administration drilling productivity report. https://www.eia.gov/petroleum/drilling/pdf/dpr-full. pdf. Accessed 18 May 2018

EIA (2018b) U.S. energy information administration natural gas gross withdrawals and production. https://www.eia.gov/dnav/ng/ng prod_sum_a_EPG0_VGM_mmcf_a.htm. Accessed 18 May 2018

Ellsworth WL (2013) Injection-induced earthquakes. Science 341:1225942

Fischer JA (1990) Proceedings of fourth U.S. national conference on earthquake engineering, Palm Springs, California, pp 649-658

Friberg P, Besana-Ostman GM, Dricker I (2014) Characterization of an earthquake sequence triggered by hydraulic fracturing in Harrison County, Ohio. Seismol Res Lett 85:1295-1307

Friberg P, Brudzinski MR, Kozłowska M, Loughner E, Langenkamp T, Dricker I (2017) Case studies of induced earthquakes in Ohio for 2016 and 2017. AGU fall meeting 2017 abstract

Friberg P, Brudzinski MR, Fasola S, Kozłowska M, Skoumal R (2018) Seismicity induced by hydraulic fracturing in Ohio in 2016: case study of the Conotton sequence in Harrison County. 36th General Assembly of the ESC abstract

Frohlich C, Hayward C, Stump B, Potter E (2011) The Dallas-Fort Worth Earthquake Sequence: October 2008 through May 2009. Bull Seismol Soc Am 101:327-340. https://doi.org/10.1785/01201 00131

Gerrish H, Nieto A (2005) Evaluation of reservoir information in relation to earthquakes in Ashtabula, Ohio. Dev Water Sci 52:377401. https://doi.org/10.1016/S0167-5648(05)52027-6

Goebel THW, Kwiatek G, Becker TW, Brodsky EE, Dresen G (2017) What allows seismic events to grow big?: insights from $b$ value and fault roughness analysis in laboratory stick-slip experiments. Geology 45:815-818. https://doi.org/10.1130/g39147.1

Gutenberg B, Richter CF (1944) Frequency of earthquakes in California. Bull Seismol Soc Am 34:185-188

Hansen MC, Ruff LJ (2003) The Ohio seismic network. Seism Res Lett 74(5):561-564 
Healy JH, Rubey WW, Griggs DT, Raleigh CB (1968) The Denver earthquakes. Science 161:1301-1310

Holland A (2013) Earthquakes triggered by hydraulic fracturing in south-central Oklahoma. Bull Seismol Soc Am 103:1784-1792

Holtkamp SG, Brudzinski MR, Currie BS (2015) Regional detection and monitoring of injection-induced seismicity: application to the 2010-2012 Youngstown, Ohio seismic sequence. Am Assoc Pet Geol Bull 99:1671-1688. https://doi.org/10.1306/03311513194

Homman KA (2015) Seismicity in Pennsylvania [M.S. thesis]: University Park, Pennsylvania State University, p 128

Hurd O, Zoback MD (2012) Intraplate earthquakes, regional stress and fault mechanics in the central and eastern US and southeastern Canada. Tectonophysics 581:182-192

Keranen KM, Savage HM, Abers GA, Cochran ES (2013) Potentially induced earthquakes in Oklahoma, USA: Links between wastewater injection and the $2011 \mathrm{Mw} 5.7$ earthquake sequence. Geology 41(6):699-702. https://doi.org/10.1130/g34045.1

Keranen KM, Weingarten M, Abers GA, Bekins BA, Ge S (2014) Sharp increase in central Oklahoma seismicity since 2008 induced by massive wastewater injection. Science 345(6195):448-451. https://doi.org/10.1126/science. 1255802

Kim W-Y (2013) Induced seismicity associated with fluid injection into a deep well in Youngstown, Ohio. J Geophys Res 118:3506-3518. https://doi.org/10.1002/jgrb.50247

Kozłowska M, Brudzinski MR, Friberg P, Skoumal RJ, Baxter N, Currie BS (2018) Maturity of nearby faults influences seismic hazard from hydraulic fracturing. Proc Nat Acad Sc 115(8):E1720E1729. https://doi.org/10.1073/pnas.1715284115

McDowell RR, Lewis JE, Dinterman PA (2014) West Virginia earthquakes: crustal adjustments along the Rome Trough or something else? Geol Soc Am Abs Programs 46(2):71

McGarr A, Bekins B, Burkardt N et al (2015) Coping with earthquakes induced by fluid injection. Science 347:830-831

Morris A, Ferrill D, Walter G, Price A, Smart K, Skoumal RJ, Brudzinski MR, Currie B (2017) Lessons learned from the Youngstown, Ohio induced earthquake sequence January 2011 to January 2012. J Rock Mech Geotech Eng 9:783-796

MRCSP - Midwest Regional Carbon Sequestration Partnership (2009) Characterization of geologic sequestration opportunities in the MRCSP Region: Middle Devonian-Middle Silurian Formations: Project Final Report: 149

Nicholson C, Roeloffs E, Wesson RL (1988) The northeastern Ohio earthquake of 31 January 1986: was it induced? Bull Seismol Soc Am 78(1):188-217

ODNR (2017a) Ohio Department of Natural Resources: Division of Oil and Gas Resources Management, AGI Policy \& Critical Issues Webinar: OhioNET: State of Ohio's Response to Induced Seismicity, April 142017

ODNR (2017b) Earthquake, Batesville, OH, Noble County, June 03, 2017. (http://geosurvey.ohiodnr.gov/quakes-2010-to-present-pgs/ batesville-june-03-2017). Accessed 1 Jan 2019

ODNR (2018a) Ohio Department of Natural Resources, Class II brine injection wells of Ohio. http://oilandgas.ohiodnr.gov/portals/oilga s/pdf/Class_II_Map/Class\%20II\%20Brine\%20Injection\%20Wel 1s\%20of\%20Ohio\%2004032017.pdf. Accessed 18 May 2018

ODNR (2018b) Ohio Department of Natural Resources Division of Oil and Gas, resources shale well drilling and permitting. http://oilan dgas.ohiodnr.gov/shale. Accessed 18 May 2018

ODNR (2018c) Ohio Department of Natural Resources Division of Oil and Gas, oil and gas well production. http://oilandgas.ohiodnr.gov/ production\#ARCH1. Accessed 18 May 2018
Rubinstein JL, Mahani AB (2015) Myths and facts on wastewater injection, hydraulic fracturing, enhanced oil recovery, and induced seismicity. Seismol Res Lett 86:1060-1067

Schoenball M, Ellsworth WL (2017) Waveform-relocated earthquake catalog for Oklahoma and Southern Kansas illuminates the regional fault network. Seismol Res Lett 88(5):1252-1258. https ://doi.org/10.1785/0220170083

Schultz R, Atkinson G, Eaton DW, Gu YJ, Kao H (2018) Hydraulic fracturing volume is associated with induced earthquake productivity in the Duvernay play. Science 359:304-308

Seeber L, Armbruster JG (1993) Natural and induced seismicity in the Lake Erie-Lake Ontario region: reactivation of ancient faults with little neotectonic displacement. Géog Phys Quatern 47:363-378

Seeber L, Armbruster JG, Kim W-Y (2004) A fluid-injection-triggered earthquake sequence in Ashtabula, Ohio: implications for seismogenesis in stable continental regions. Bull Seismol Soc Am 94(1):76-87. https://doi.org/10.1785/0120020091

Skoumal RJ, Brudzinski MR, Currie BS, Levy J (2014) Optimizing multi-station earthquake template matching through re-examination of the Youngstown, Ohio sequence. Earth Planet Sci Lett 405:274-280

Skoumal RJ, Brudzinski MR, Currie BS (2015a) Induced earthquakes during hydraulic fracturing in Poland Township. Ohio. Bull Seismol Soc Am 105(1):189-197. https://doi.org/10.1785/01201 40168

Skoumal RJ, Brudzinski MR, Currie BS (2015b) Microseismicity induced by deep wastewater injection in Southern Trumbull County, Ohio. Seismol Res Lett 86(5):1326-1334. https://doi. org/10.1785/0220150055

Skoumal RJ, Brudzinski MR, Currie BS (2015c) Distinguishing induced seismicity from natural seismicity in Ohio: demonstrating the utility of waveform template matching. J Geophys Res Solid Earth 120:6284-6296. https://doi.org/10.1002/2015JB012265

Skoumal RJ, Brudzinski MR, Currie BS (2016) An efficient repeating signal detector to investigate earthquake swarms. J Geophys Res Solid Earth 121:5880-5897. https://doi.org/10.1002/2016J B012981

Skoumal RJ, Brudzinski MR, Currie BS (2018) Proximity of Precambrian basement affects the likelihood of induced seismicity in the Appalachian, Illinois, and Williston Basins, central and eastern United States. Geosphere 14(3):1365-1379. https://doi. org/10.1130/GES01542.1

Snee J-EL, Zoback M (2018) State of stress in the Permian Basin, Texas and New Mexico: implications for induced seismicity. Lead Edge 37(2):127-134. https://doi.org/10.1190/tle37020127.1

Waldhauser F, Ellsworth WL (2000) A double-difference earthquake location algorithm: method and application to the northern Hayward Fault, California. Bull Seismol Soc Am 90:1353-1368

Walsh FR, Zoback MD (2015) Oklahoma's recent earthquakes and saltwater disposal. Sci Adv 1(5):e1500195. https://doi.org/10.1126/ sciadv. 1500195

Weingarten M, Ge S, Godt JW, Bekins BA, Rubinstein JL (2015) Highrate injection is associated with the increase in U.S. mid-continent seismicity. Science 348:1336-1340

Wiemer S, Wyss M (2000) Minimum magnitude of completeness in earthquake catalogs: examples from Alaska, the western United States, and Japan. Bull Seismol Soc Am 90(4):859-869 